\title{
Protective role of $17 \beta$-estradiol treatment in renal injury on female rats submitted to brain death
}

\author{
Roberto Armstrong-Jrr ${ }^{1 \#}$, Fernanda Yamamoto Ricardo-da-Silva ${ }^{1 \#}{ }^{\wedge}$, Marina Vidal-dos-Santos ${ }^{1} \wedge$, \\ Cristiano de Jesus Correia ${ }^{1} \wedge$, Lucas Ferreira Anunciação ${ }^{1 \wedge}$, Raphael dos Santos Coutinho e Silva ${ }^{1 \wedge}$, \\ Luiz Felipe Pinho Moreira ${ }^{1}$, Henri Gerrit Derk Leuvenink ${ }^{2}$, Ana Cristina Breithaupt-Faloppa ${ }^{1 \wedge}$ \\ ${ }^{1}$ Laboratorio de Cirurgia Cardiovascular e Fisiopatologia da Circulação (LIM-11), Instituto do Coração (InCor), Faculdade de Medicina da \\ Universidade de São Paulo, São Paulo, Brazil; ${ }^{2}$ Department of Surgery, University Medical Centre Groningen, University of Groningen, Groningen, \\ The Netherlands \\ Contributions: (I) Conception and design: R Armstrong-Jr, FY Ricardo-da-Silva, HGD Leuvenink, AC Breithaupt-Faloppa; (II) Administrative \\ support: CJ Correia, AC Breithaupt-Faloppa; (III) Provision of study materials or patients: LFP Moreira, AC Breithaupt-Faloppa; (IV) Collection \\ and assembly of data: R Armstrong-Jr, FY Ricardo-da-Silva, CJ Correia, LF Anunciação, RS Coutinho e Silva; (V) Data analysis and interpretation: \\ R Armstrong-Jr, FY Ricardo-da-Silva, CJ Correia, LFP Moreira, AC Breithaupt-Faloppa; (VI) Manuscript writing: All authors; (VII) Final approval \\ of manuscript: All authors. \\ "These authors contributed equally to this work. \\ Correspondence to: Ana Cristina Breithaupt-Faloppa, PhD. Laboratório de Cirurgia Cardiovascular e Fisiopatologia da Circulação (LIM/11) - HC- \\ FMUSP, Universidade de São Paulo, Av. Dr. Arnaldo, $4552^{\circ}$ andar - sala 2146 - 01246-903 São Paulo, Brazil. Email: ana.breithaupt@hc.fm.usp.br.
}

\begin{abstract}
Background: Clinical and experimental data highlight the consequences of brain death on the quality of organs and demonstrate the importance of donor state to the results of transplantation. Female rats show higher cardio-pulmonary injury linked to decreased concentrations of female sex hormones after brain-dead (BD). This study evaluated the effect of $17 \beta$-estradiol on brain death induced renal injury in female rats.

Methods: Female Wistar rats were randomically allocated into 4 groups: false-operation (Sham), BD, treatment with $17 \beta$-estradiol $(50 \mu \mathrm{g} / \mathrm{mL}, 2 \mathrm{~mL} / \mathrm{h}) 3 \mathrm{~h}$ after brain death (E2-T3), or immediately after brain death confirmation (E2-T0). Creatinine, urea, cytokines, and complement system components were quantified. Renal injury markers, such as KIM-1, Caspase-3, BCL-2 and MMP2/9 were evaluated.

Results: Brain death leads to increased kidney KIM-1 expression and longer $17 \beta$-estradiol treatment resulted in downregulation $(\mathrm{P}<0.0001)$. There was increase of neutrophil numbers in kidney from $\mathrm{BD}$ rats and $\mathrm{E} 2$ treatment was able to reduce it $(\mathrm{P}=0.018)$. Regarding complement elements, E2-T3 group evidenced E2 therapeutic effects, reducing C5b-9 $(\mathrm{P}=0.0004), \mathrm{C} 3 \mathrm{aR}(\mathrm{P}=0.054)$ and $\mathrm{C} 5 \mathrm{aR}(\mathrm{P}=0.019)$. In parallel, there were $17 \beta$-estradiol effects in reducing MMP2 ( $\mathrm{P}=0.0043)$, MMP9 $(\mathrm{P}=0.011)$, and IL-6 $(\mathrm{P}=0.024)$. Moreover, E2-T3 group improved renal function in comparison to BD group $(\mathrm{P}=0.0938)$.

Conclusions: $17 \beta$-estradiol treatment was able to reduce acute kidney damage in BD female rats owing to its ability to prevent tissue damage, formation of C5b-9, and local synthesis of inflammatory mediators.
\end{abstract}

Keywords: Brain death; estradiol; inflammation; kidney; female Wistar rats

Submitted Mar 23, 2021. Accepted for publication Jun 03, 2021.

doi: $10.21037 /$ atm-21-1408

View this article at: https://dx.doi.org/10.21037/atm-21-1408

\footnotetext{
^ ORCID: Roberto Armstrong-Jr, 0000-0002-5228-3992; Fernanda Yamamoto Ricardo-da-Silva, 0000-0003-3495-8551; Marina Vidaldos-Santos, 0000-0002-6965-5326; Cristiano de Jesus Correia, 0000-0002-1690-9951; Lucas Ferreira Anunciação, 0000-0002-03984370; Raphael dos Santos Coutinho e Silva, 0000-0001-8818-5043; Luiz Felipe Pinho Moreira, 0000-0003-0179-4976; Henri Gerrit Derk Leuvenink, 0000-0001-5036-2999; Ana Cristina Breithaupt-Faloppa, 0000-0003-0554-0674.
} 


\section{Introduction}

Kidney transplantation is considered the ideal treatment for patients with end-stage renal disease (1). Donor organ shortage has consequently led to the acceptance of lower quality organs for transplantation and now the use of older and not ideal donors is routine (2). Brain-dead (BD) patients represent as organ donors an important addition to the number of renal transplants (3). Clinical and experimental studies highlight the influence of $\mathrm{BD}$ on the viability of the organs and demonstrate the importance of donor state to the results of transplantation (4). Preventing/reverting the brain death deleterious effects on kidneys could positively influence transplantation and increase the number of available organs (3).

Brain death affects the endocrine responses and the changes in hormonal milieu lead to the rationale for hormone replacement therapy for BD patients. Sex hormones are important to the maintenance of the functional activity of organs and previous studies have identified the association of the BD induced acute estradiol reduction in female rats to a worst inflammatory profile in hearts, lungs, and intestine in relation to male donor profiles (5-7). In female rats, BD results in more edema, hemorrhagic foci and recruitment of inflammatory cells to lungs and heart (6). 17 $\beta$-estradiol (E2) treatment is able to prevent heart injury caused by BD in female rats (8). Moreover, previous results pointed to E2 therapeutic effects reducing the release of chemokines, hindering cell traffic into female rat lungs (9). In this context, we aimed to investigate the effects of E2 treatment on the deleterious processes in the kidneys of female rats submitted to BD.

We present the following article in accordance with the ARRIVE reporting checklist (available at https://dx.doi. org/10.21037/atm-21-1408).

\section{Methods}

\section{Animals}

Female Wistar rats that were $7-8$ weeks old $(\mathrm{n}=32)$ were acquired from our animal facilities. Before the experimental procedure, all animals were housed at $23 \pm 2{ }^{\circ} \mathrm{C}$ in a 12 -h light-dark cycle with access to water and food ad libitum. The animals received humane care in compliance with the ARRIVE guidelines and the 'Principles of Laboratory Animal Care' formulated by the National Society for Medical Research and the 'Guide for the Care and Use of
Laboratory Animals' prepared by the Institute of Laboratory Animal Resources and published by the National Institutes of Health (NIH Publication No. 86-23, revised 1996). The experimental protocol was approved by the Animal Subject Committee of Sao Paulo University Medical School (SDC No. 4350/16/016).

\section{Groups and treatment}

For this study, female rats were used for maximal estradiol secretion to the proestrus and estrous phases of the cycle and randomized into four groups: (I) Sham: rats subjected to trepanation without $\mathrm{BD}$ induction; (II) BD: rats subjected to BD induction; (III) E2-T0: rats administered E2 in saline $(50 \mu \mathrm{g} / \mathrm{mL}$ to $2 \mathrm{~mL} / \mathrm{h}$; Sigma-Aldrich, St. Louis, Missouri, USA) immediately after BD induction and continuously until the end of the experiment; (IV) E2T3: rats administered $\mathrm{E} 2$ in saline $(50 \mu \mathrm{g} / \mathrm{mL}$ to $2 \mathrm{~mL} / \mathrm{h}$; Sigma-Aldrich, St. Louis, Missouri, USA) $3 \mathrm{~h}$ after BD induction and continuously until the end of the experiment (Figure 1). Sham and BD groups received fluid replacement (saline solution, $2 \mathrm{~mL} / \mathrm{h}$ ). The $\mathrm{E} 2 \mathrm{administered}$ is associated with cyclodextrine in order to allow its water-solubility (Sigma-Aldrich, St. Louis, Missouri, USA). BD and Sham groups received the correspondent volume of cyclodextrine to discard effects of this vehicle. A group of nonmanipulated rats were used to obtain reference parameters (- - ) as a line for all data presented.

\section{Estrous cycle verification and serum estradiol quantification}

Phosphate-buffered saline (PBS) was used for vaginal lavage procedure, placed in glass slides and stained with crystal violet solution $(0.2 \%)$. The estrus and proestrus cycles were recognized using an optical microscope. In order to verify estradiol levels after the experimental period, serum samples were used in ELISA assay following manufacturer's instructions (Cayman Chemical Company, USA).

\section{Brain death model}

$\mathrm{BD}$ induction was based on the method published by Breithaupt-Faloppa et al. [2016] (5). Anesthesia was induced in a closed chamber with $5 \%$ isoflurane, followed by intubation and mechanical ventilation (Harvard Apparatus, model 683, Holliston, Massachusetts USA) at a tidal volume of $10 \mathrm{~mL} / \mathrm{kg}, 70$ breaths $/ \mathrm{min}$ and of $2 \%$ isoflurane. Blood sampling under constant blood pressure-monitoring was 


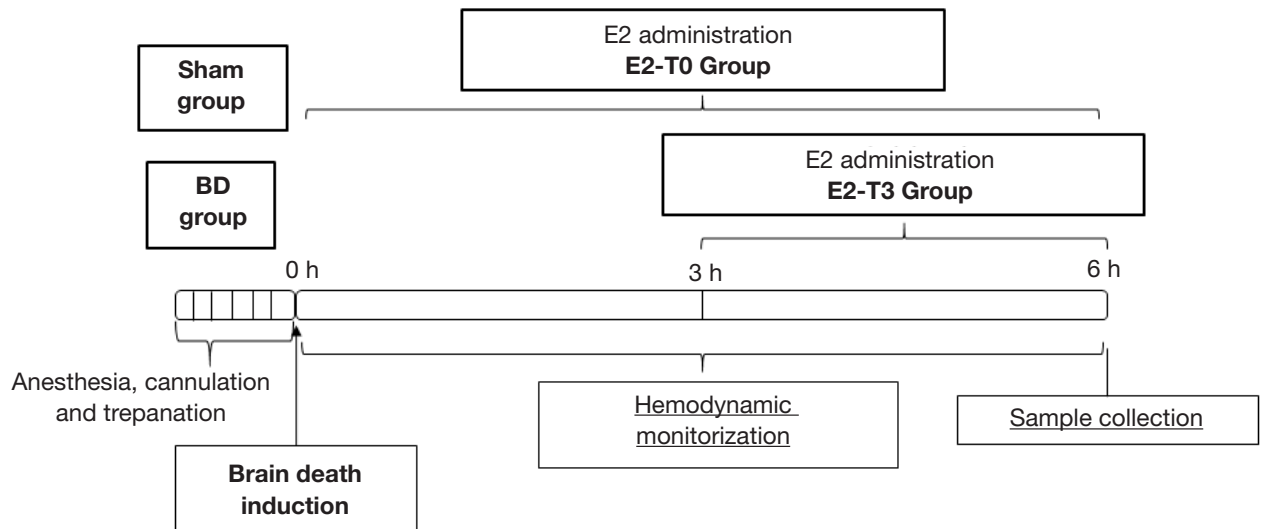

Figure 1 Experimental timeline. Sham, false-operated rats; BD, rats submitted to BD; E2-T0, 17 $\beta$-estradiol (E2)-treated rats after confirmation of BD and E2-T3, 17 $\beta$-estradiol (E2)-treated rats after $3 \mathrm{~h}$ of confirmation of BD. BD, brain death.

obtained from a cannula inserted in the carotid artery. Saline solution $(2 \mathrm{~mL} / \mathrm{h})$, with or without treatment, was infused into the jugular vein. A Fogarty $4 \mathrm{~F}$ catheter (Baxter Healthcare Co., Deerfield, Illinois, USA) was inserted intracranially through a parietal drilled hole. BD was induced by rapid balloon inflation ( $400 \mu \mathrm{L}$, saline solution), established through the absence of reflexes, mydriasis, and then isoflurane inhalation was interrupted. Sham animals were maintained anesthetized with isoflurane during the whole experimental period. All animals were maintained and monitored for $6 \mathrm{~h}$.

\section{Quantification of serum levels of creatinine and urea}

Creatinine and urea concentrations in serum were measured colorimetrically, using a commercial kit according to the manufacturer's specifications (Bioclin/Quibasa, Minas Gerais, Brazil).

\section{Histopatbologic kidney analysis}

Kidney samples were obtained and fixed in $10 \%$ formaldehyde for $24 \mathrm{~h}$, embedded in paraffin, sectioned $(4 \mu \mathrm{m})$, and stained with hematoxylin and eosin. Leukocyte infiltration was evaluated by two observers blinded for intervention. The obtained mean values were analyzed by correlation tests to determine inter-observer variability. Leukocyte infiltration was reported in cells per square millimeter of renal tissue.

\section{Immunobistochemistry}

Cryosections of the kidney tissue (8- $\mu \mathrm{m}$ thick) were fixed in acetone for $10 \mathrm{~min}$. The sections were washed in Trisbuffered saline Tween-20 (TBST), permeabilized with TBST and Triton X-100, the non-specific sites were blocked with TBST, containing $3 \%$ bovine serum albumin (BSA), and then blocked with endogenous peroxidase $\left(\mathrm{H}_{2} \mathrm{O}_{2}\right.$, $2 \%$ ). Sections were incubated at $37^{\circ} \mathrm{C}$ for $1 \mathrm{~h}$ with primary antibodies in TBST/BSA: rabbit anti-rat antibodieskidney injury marker (KIM)-1 (1:100; Boster, Pleasanton, USA), Caspase-3 (1:50; Abcam, Cambridge, UK), BCL2 (1:100; Boster, Pleasanton, USA), and metalloproteinase (MMP)-9 (1:100; Abcam, Cambridge, UK); mouse antirat antibodies-membrane attack complex (C5b-9) (1:100; Hycult biotech, Uthen, NL), MMP2 (1:100; Abcam, Cambridge, UK); and goat anti-rat antibody-C3 (1:200; Abcam, Cambridge, UK). Next, a 1:400 horseradish peroxidase-conjugated (HRP) secondary antibody was applied to the sections at $37^{\circ} \mathrm{C}$ for $1 \mathrm{~h}$ (EMD Millipore Corporation). Next, staining was performed using HRP substrate (3-amino-9-ethylcarbazole or diaminobenzidine DAB; Vector Laboratories, Burlingame, California, USA) for 5-10 $\mathrm{min}$. Stained areas were identified in the glomerular area, after determining a threshold, and analysis of staining area fractions was carried out with an image analyzer (NIS-Elements; Nikon, Minato City, Tokyo, JP). Background was determined by sections incubated in the absence of the primary antibody as a negative control.

Kidney tissue paraffin sections $(4 \mu \mathrm{m})$ were rehydrated 
and treated with EDTA (pH 8.0) 15 min at $95^{\circ} \mathrm{C}$ for antigen retrieval. First endogenous peroxidase was blocked $\left(\mathrm{H}_{2} \mathrm{O}_{2}\right.$, $0.3 \%)$. Immunohistochemistry used myeloperoxidase (MPO) 1:20 primary antibody (anti-MPO, Abcam, UK), 1:100 secondary antibody (goat anti-rabbit, Dako, USA) and 1:100 third antibody (rabbit anti-goat, Dako). Finally, we developed the reaction with 3,3'-diaminobenzidine (DAB, Thermo Fisher Scientific, USA) and counter stained with haematoxylin. Negative controls were performed by incubating sections in the absence of the primary antibody. We used NIS-Elements software (Nikon) for determining and quantifying stained cells. The data was expressed as number of MPO stained cells $/ \mathrm{mm}^{2}$.

\section{Gene expression evaluation}

Kidney tissue samples were stored at $-80{ }^{\circ} \mathrm{C}$. RNA was extracted using a commercial mirVana Kit (Ambion, Austin, Texas, USA). The cDNA was transcribed with reverse transcriptase (High-Capacity Reverse Transcriptase Kit, Applied Biosystems, Foster City, California, USA). RT-PCR was conducted using SYBR Green PCR Realtime PCR (RT-PCR) Master Mix (Applied Biosystems) and SYBR Green primers (Applied Biosystems) against $\beta$-actin, kidney injury marker-1 (KIM-1), Caspase-3, BCL2, C3, C3aR, C5aR, decay-accelerating factor (DAF), membrane attack complex-inhibitor protein (MAC-IP/ CD59), interleukin (IL)-1 $\beta$, and IL-6 (Table 1). Targets were amplified over 1 cycle for $2 \mathrm{~min}$ at $50^{\circ} \mathrm{C}, 1$ cycle for $10 \mathrm{~min}$ at $95{ }^{\circ} \mathrm{C}$, and 40 cycles for $15 \mathrm{~s}$ at $95^{\circ} \mathrm{C}$ and for $1 \mathrm{~min}$ at $60{ }^{\circ} \mathrm{C}$.

In parallel, glyceraldehyde-3-phosphate dehydrogenase (GAPDH), metalloproteinase (MMP)-2, and MMP9 target genes (Table 1) were amplified with TaqMan primers (Applied Biosystems) and TaqMan Universal PCR Master Mix (Applied Biosystems) over 1 cycle for $2 \mathrm{~min}$ at $50{ }^{\circ} \mathrm{C}$, 1 cycle for $10 \mathrm{~min}$ at $95^{\circ} \mathrm{C}$, and 40 cycles for 15 seconds at $95{ }^{\circ} \mathrm{C}$ and for 1 minute at $60{ }^{\circ} \mathrm{C}$. Relative gene expression was determined in relation to the values of naive animals $(n=4)$.

\section{Homogenization of renal tissue}

Kidney fragments were weighed and homogenized in PBS $(3 \mathrm{~mL} / \mathrm{g}$ ) using a gentleMACS Dissociator (Miltenyi Biotec, Bergisch Gladbach, North Rhine-Westphalia, Germany) and stored at $-80{ }^{\circ} \mathrm{C}$ for analysis.

\section{Quantification of inflammatory mediators}

Interleukin (IL)-1 $\beta$, IL-6, and vascular endothelial growth factor (VEGF) were quantified in renal tissue homogenate by enzyme-linked immunosorbent assay (ELISA) following the manufacturer's instructions (R\&D Systems, Minneapolis, Minnesota, USA).

Quantification of the serum levels of complement component C3 was performed by ELISA (Abcam, Cambridge, Massachusetts, USA).

\section{Statistical analysis}

Study data are expressed as mean \pm standard error (SEM) or as median and $95 \%$ percentile interval (abnormal distribution). The data regarding kidney function was submitted to two-way ANOVA test. All other data, KruskalWallis test followed by post-hoc Dunn multiple comparison test was performed, with $\mathrm{P}$ values normalized to account for multiple comparisons. Statistical analysis was executed with GraphPad Prism software v.9.1 (GraphPad, San Diego, California, USA) and values of $\mathrm{P} \leq 0.05$ were considered significant.

\section{Results}

The E2 treatment was based on previous studies $(8,9)$, using the same model of $\mathrm{BD}$, in which both treated groups presented similar increases in serum estradiol levels after the end of $\mathrm{E} 2$ infusion compared to the $\mathrm{BD}$ group $(\mathrm{BD}=68.2 \pm 8$, $\mathrm{E} 2-\mathrm{T} 0=1,713.5 \pm 44.7, \mathrm{E} 2-\mathrm{T} 3=1,717.9 \pm 29.2 \mathrm{pg} / \mathrm{mL}$; $\mathrm{P}<0.05)$.

\section{Mean arterial pressure (MAP) and renal function}

As illustrated in Figure 2A, the BD led to a sudden increase in intracranial pressure, resulting in a transient hypertensive crisis followed by a period of hypotension and, finally, normalization of MAP. Regarding to E2 treatment, there were no relevant differences in MAP over experimental time between treated groups.

The BD group had an increase in the serum creatinine levels at the end of the experiment compared to the Sham group. On the other hand, the E2-T3 group exhibited lower serum creatinine levels than the BD group (Figure $2 B$ ).

Moreover, all groups showed an increase in urea levels after $6 \mathrm{~h}$ in relation to the initial value; however, these 
Table 1 Primers sequence used for RT-PCR analysis

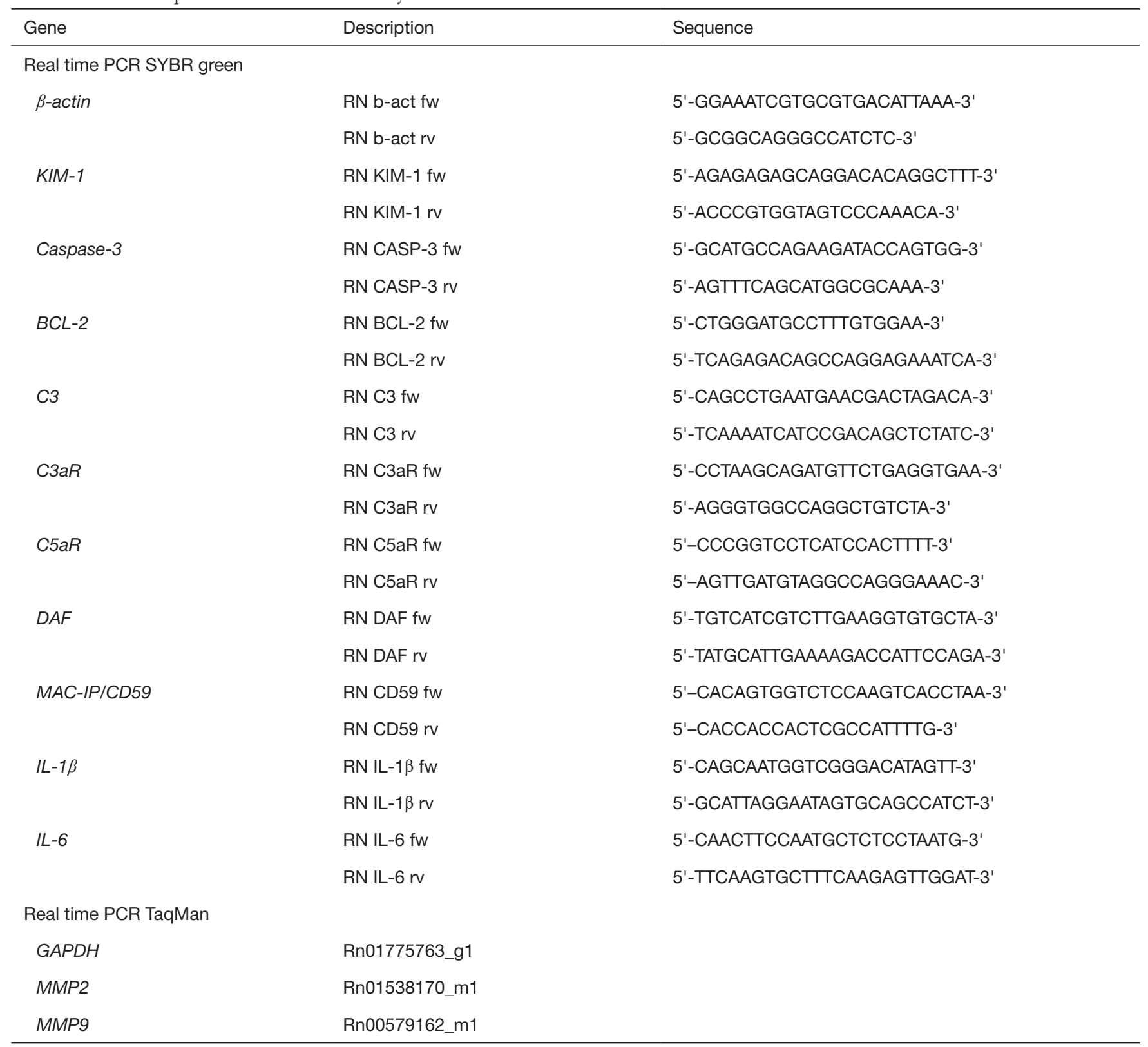

RT-PCR, real-time polymerase chain reaction; KIM, kidney injury marker; DAF, decay accelerating factor; MAC-IP, membrane attack complex- inhibitor protein; IL, interleukin; GAPDH, glyceraldeyde-3-phosphate dehydrogenase; MMP, matrix metalloproteinase.

values did not differ among the groups (Figure 2C).

\section{Histopathological analysis}

No difference was observed in leukocyte influx among the groups (Figure $3 A$ ). The leukocyte staining for MPO showed increased neutrophil numbers in BD rats
(Figure $3 B$ ). The E2 treatment for $3 \mathrm{~h}$ was able to reduce the neutrophil infiltrate to the kidneys.

\section{KIM-1}

KIM-1 is the most highly upregulated protein in the proximal tubule of the kidney after injury (3) and has 

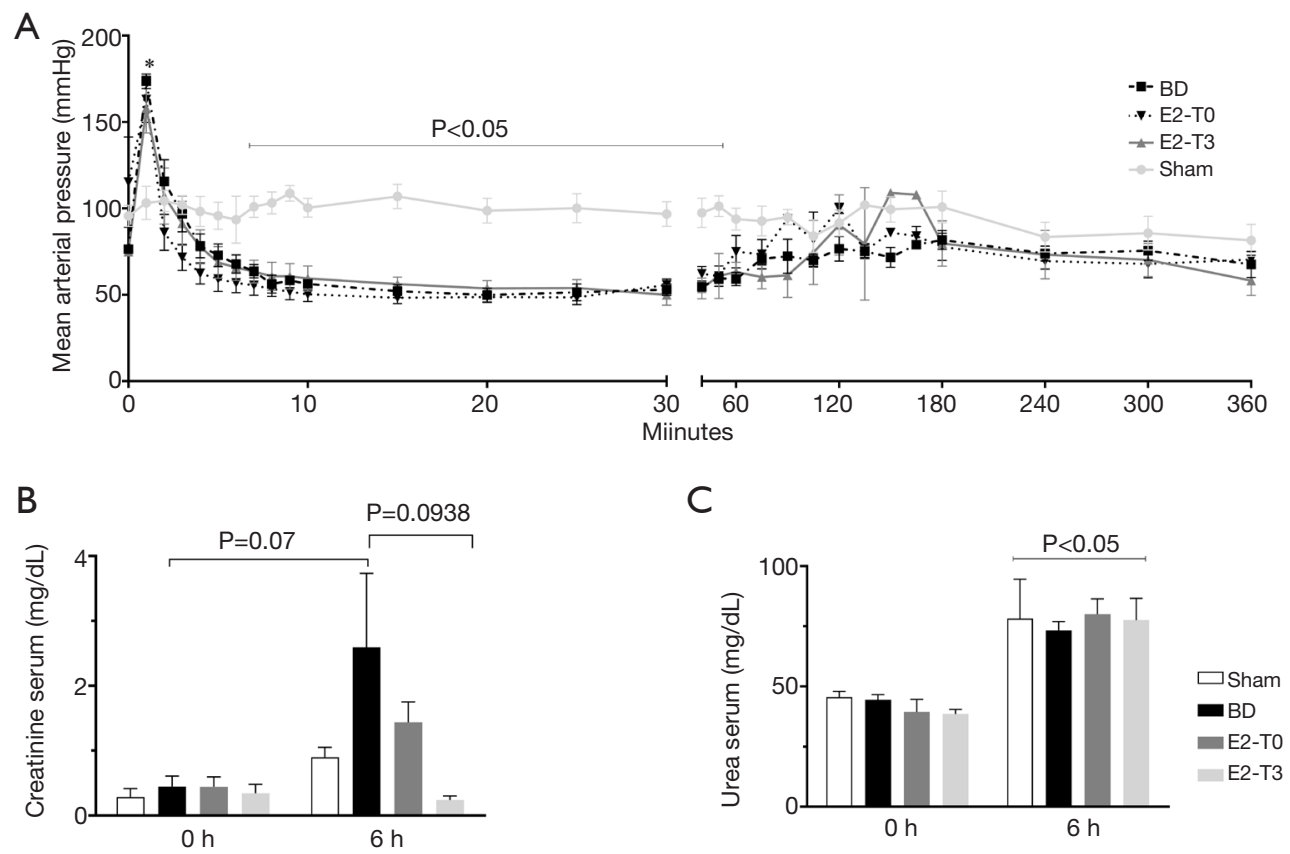

Figure 2 Mean arterial pressure (A), serum (B) creatinine and (C) urea levels. Sham, false-operated rats; BD, rats submitted to BD; E2T0, 17 $\beta$-estradiol (E2)-treated rats after confirmation of BD and E2-T3, 17 $\beta$-estradiol (E2)-treated rats after $3 \mathrm{~h}$ of confirmation of BD. Values represent the mean \pm SEM ( $n=7)$. Statistical analysis: ANOVA (A) $\mathrm{P}=0.019$; (B) $\mathrm{P}^{\text {Groups }}=0.114$ and $\mathrm{P}^{\text {Time }}=0.025(\mathrm{C}) \mathrm{P}^{\text {Groups }}=0.955$ and $\mathrm{P}^{\text {Time }}<0.0001$ (GraphPad Prism software v.9.1). * $\mathrm{P}<0.05$. BD, brain death; ANOVA, analysis of variance.

proved to be an indicator of kidney injury in the rat. Our results showed that, in comparison to the Sham group, higher values of KIM-1 protein expression were seen in the $\mathrm{BD}$ group. In contrast, treatment with $\mathrm{E} 2$ significantly decreased KIM-1 protein expression in renal tissue (Figure 4A). No differences were detected among the groups in KIM-1 gene expression (Figure 4B).

\section{Caspase-3 and BCL-2 expression}

In order to evaluate the cell death pathway, we based our evaluation in the expression of pro-apoptotic protein, caspase- 3 and the expression of anti-apoptotic protein, BCL-2, as previously studied in the heart (8). With respect to the expression of the apoptotic protein, Caspase-3, higher values were found in the BD group in protein (Figure 5A). In contrast, lower values were found in groups E2-T0 and E2-T3 in terms of Caspase-3 protein expression analysis. No relevant differences were found among groups for protein expression of the anti-apoptotic protein, BCL2 (Figure 5B). Besides, no significant difference was found with respect to Caspase- 3 and $B C L-2$ gene expression (Figure 5C,D).

\section{Complement system components}

In BD organ donors, systemically and locally activated complement is an important mediator of inflammation and graft injury (3). With respect to complement cascade activation, there were no significant differences among groups in serum C3 levels, but higher values were found in the $\mathrm{BD}$ group and lower values were found in groups E2-T0 and E2-T3 (Figure 6A). Following the cascade, BD increased $\mathrm{C} 3$ deposition in the glomerulus of $\mathrm{BD}$ female rats in relation to the Sham group, but without significant alteration within the treated groups (Figure 6B). Further, there were no differences in the expression of $\mathrm{C} 3$ in renal tissue (Figure 6C).

Regarding terminal complement system pathway activation, higher values were seen in the $\mathrm{BD}$ group in the formation of $\mathrm{C} 5 \mathrm{~b}-9$, reduced only with treatment by $\mathrm{E} 2$ after $3 \mathrm{~h}$ of BD (Figure 6D).

Regarding the analysis of renal gene expression of complement receptors, in relation to the Sham group, BD upregulated the expression of $\mathrm{C} 3 \mathrm{aR}$ without changing the gene expression of $\mathrm{C} 5 \mathrm{aR}$. In contrast, only treatment with $\mathrm{E} 2$ after $3 \mathrm{~h}$ of $\mathrm{BD}$ was able to downregulate the expression 
A
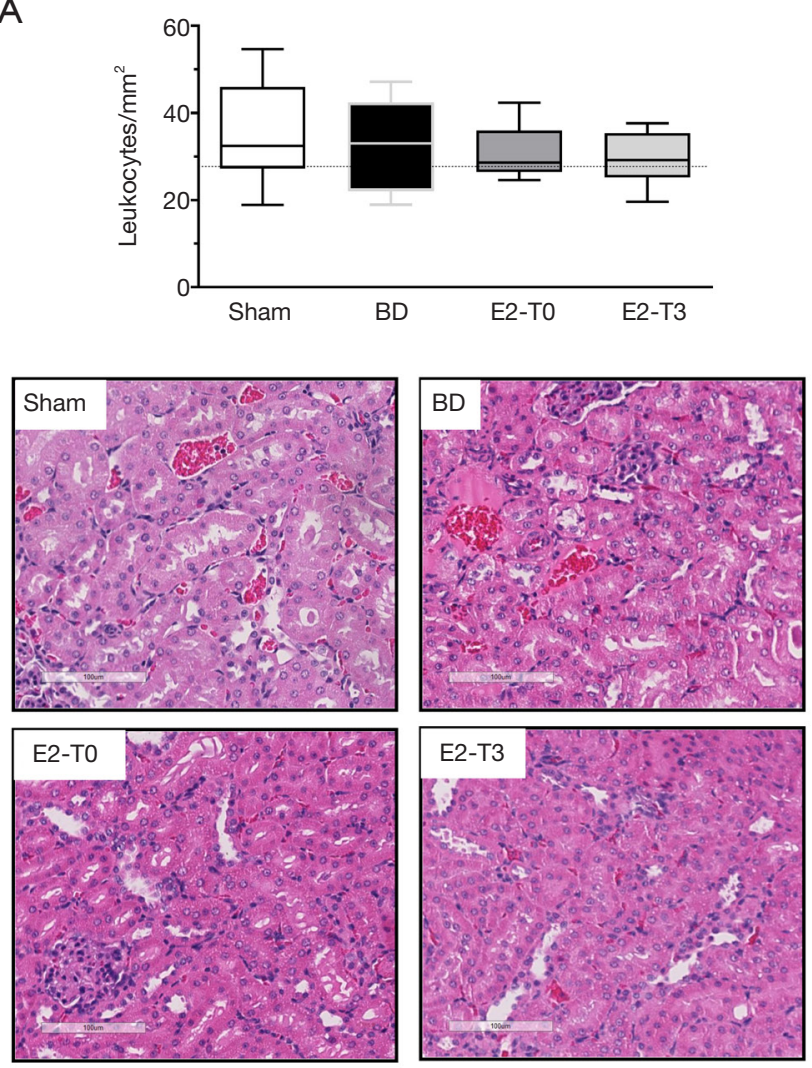

B
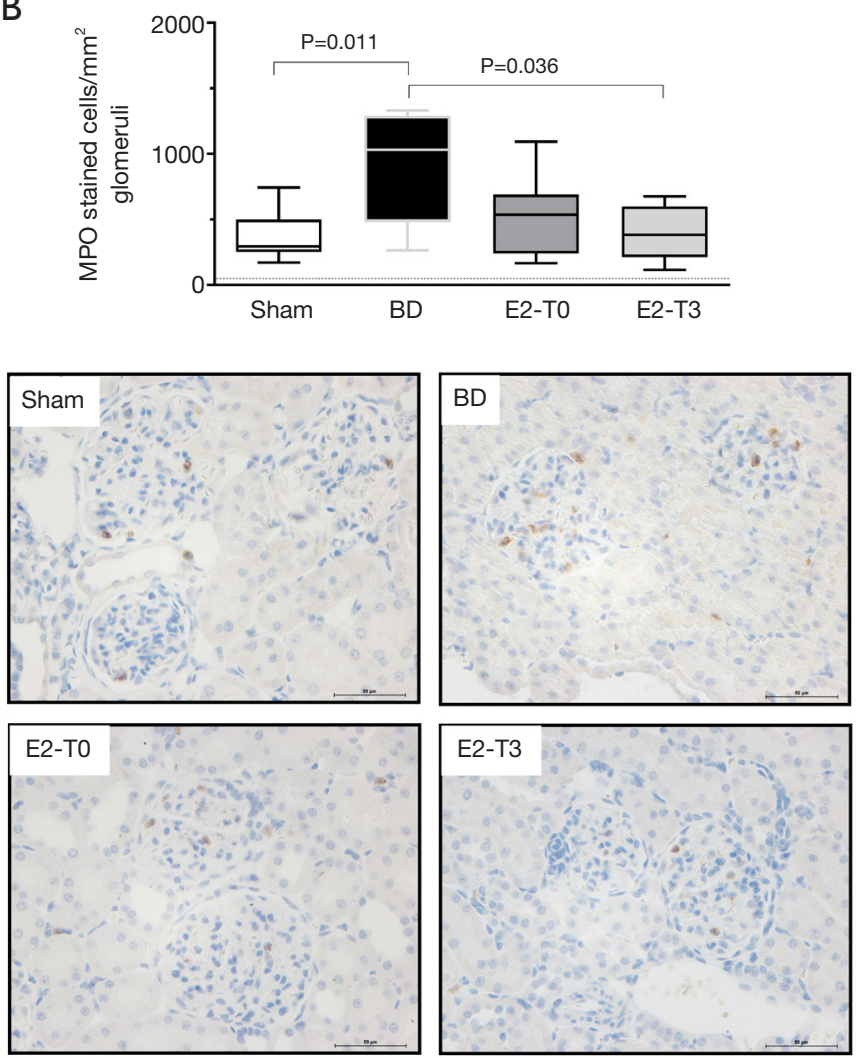

Figure 3 Analysis of leukocyte infiltration in renal tissue. (A) Leukocyte infiltration and (B) MPO stained cells. Sham, false-operated rats; $\mathrm{BD}$, rats submitted to $\mathrm{BD}$; E2-T0, 17 $\beta$-estradiol (E2)-treated rats after confirmation of BD and E2-T3, 17 $\beta$-estradiol (E2)-treated rats after 3 h of confirmation of BD. (A) Formaldehyde-fixed sections of renal tissue were stained with hematoxylin and eosin. (B) Immunohistochemical analysis of MPO expression in kidney sections. Original magnification images: 20x for all images. Values represent the median and $95 \%$ percentile interval ( $\mathrm{n}=6$ per group; 1 tissue section per animal, 10 fields). Statistical analysis: Kruskal-Wallis (A) $\mathrm{P}=0.0639$ and (B) $\mathrm{P}=0.018$ (GraphPad Prism software v.9.1). MPO, myeloperoxidase; BD, brain death.
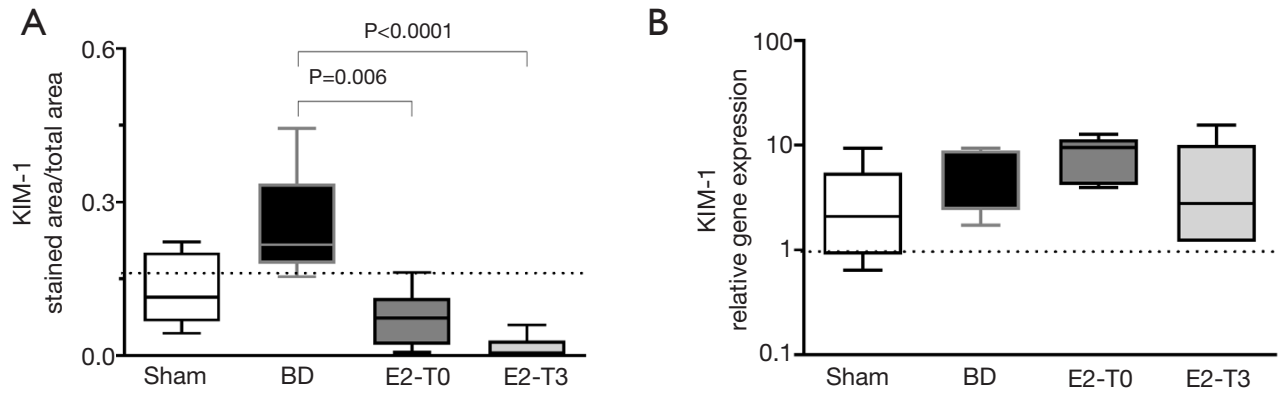

Figure 4 Protein (A) and gene expression (B) of KIM-1 in renal tissue. Sham, false-operated rats; BD, rats submitted to BD; E2-T0, $17 \beta$-estradiol (E2)-treated rats after confirmation of BD and E2-T3, 17 -estradiol (E2)-treated rats after 3 h of confirmation of BD. Values represent the median and 95\% percentile interval. (A) Imunohistochemical analysis 5 photos/sample, 1 sample/rat and 6 rats/group. (B) Gene expression levels are relative to those in naïve rats. Statistical analysis: Kruskal-Wallis (A) $\mathrm{P}<0.0001$ and (B) $\mathrm{P}=0.078$ (GraphPad Prism software v.9.1). KIM, kidney injury marker; BD, brain death. 


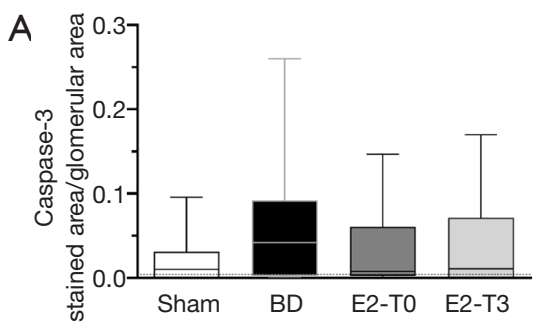

C

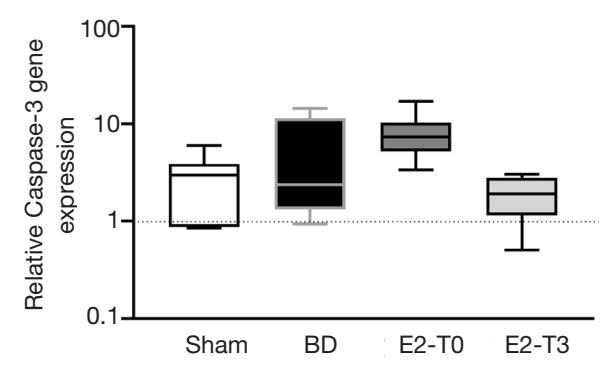

B

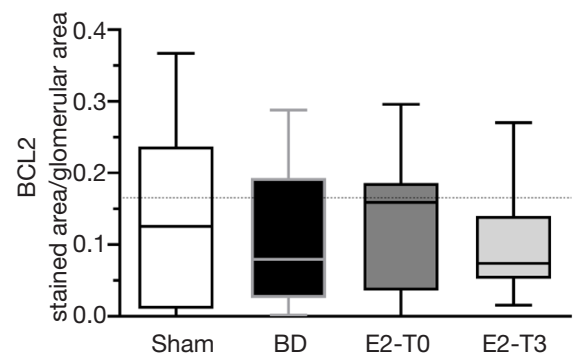

D

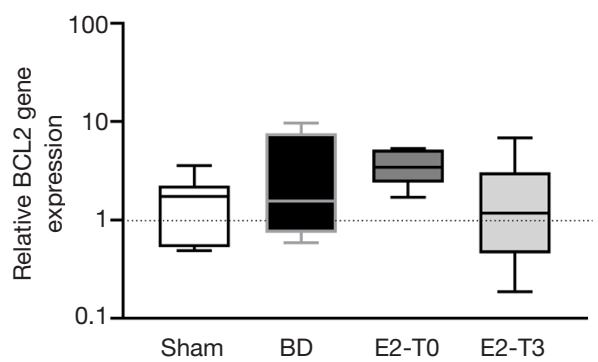

Figure 5 Protein and gene expression of Caspase-3 (A,C) and BCL-2 (B,D). Sham, false-operated rats; BD, rats submitted to BD; E2-T0, $17 \beta$-estradiol (E2)-treated rats after confirmation of BD and E2-T3, 17 -estradiol (E2)-treated rats after 3 h of confirmation of BD. Values represent the median and 95\% percentile interval. (A,B) Imunohistochemical analysis 5 photos/sample and 2 samples/animal. (C,D) Gene expression levels are relative to those in naïve rats in 5 animals/group. Statistical analysis: Kruskal-Wallis (A) $\mathrm{P}=0.188$, (B) $\mathrm{P}=0.561$, (C) $\mathrm{P}=0.016$ and (D) $\mathrm{P}=0.199$ (GraphPad Prism software v.9.1). BD, brain death.

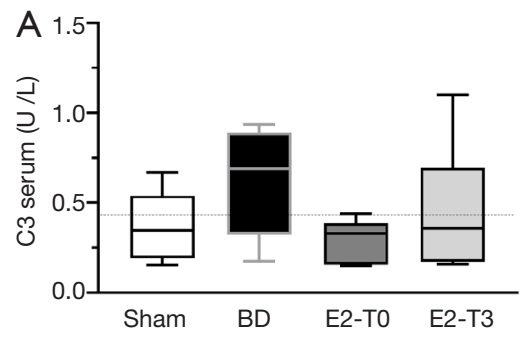

B
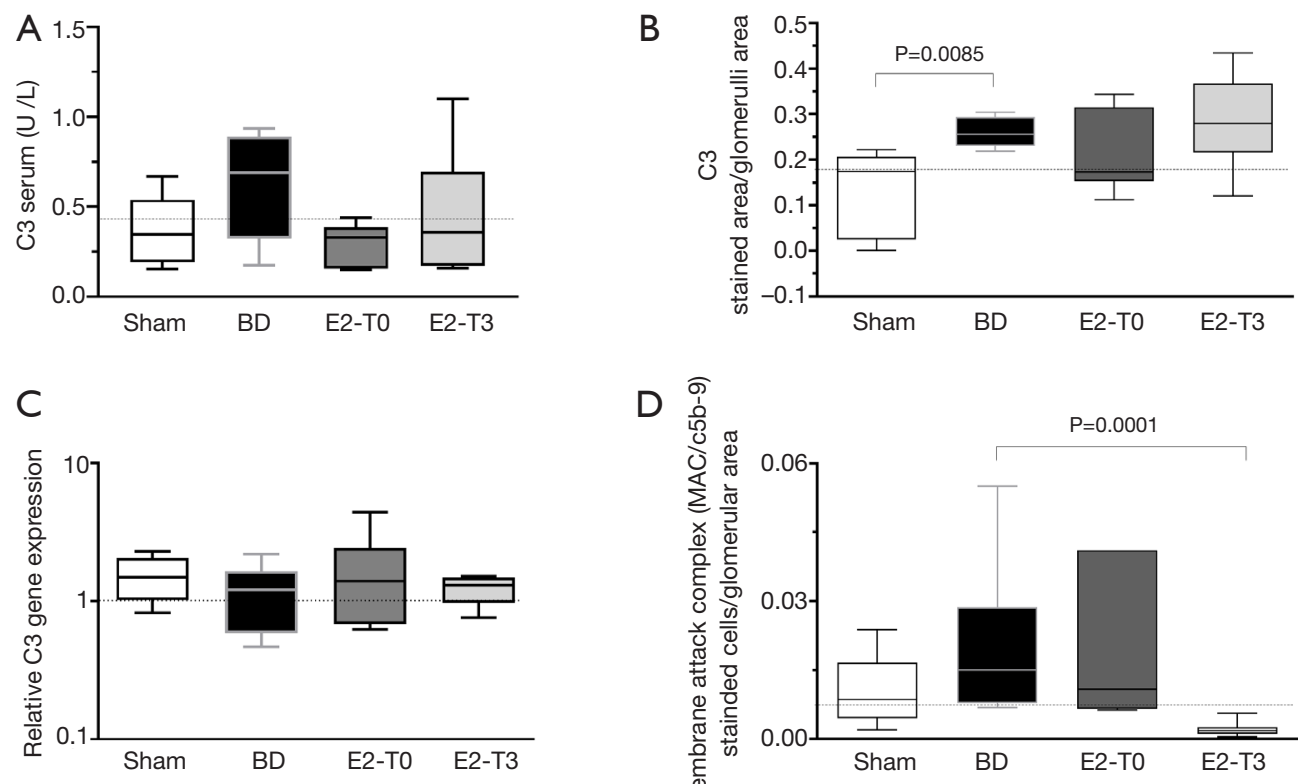

$\mathrm{D}$

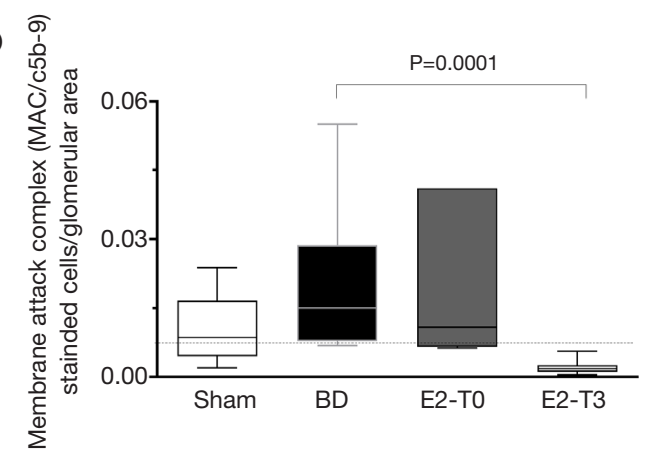

Figure 6 Quantification of C3 in serum (A); protein (B) and gene expression (C); membrane attack complex (MAC/C5b-9) protein expression (D) in renal tissue. Sham, false-operated rats; BD, rats submitted to BD; E2-T0, 17ß-estradiol (E2)-treated rats after confirmation of BD and E2-T3, 17 $\beta$-estradiol (E2)-treated rats after $3 \mathrm{~h}$ of confirmation of BD. Values represent the median and $95 \%$ percentile interval. (B,D) Imunohistochemical analysis 5 photos/sample, 1 sample/rat and 6 rats/group. (C) Gene expression levels are relative to those in naïve rats. Statistical analysis: Kruskal-Wallis (A) $\mathrm{P}=0.112$, (B) $\mathrm{P}=0.004$, (C) $\mathrm{P}=0.827$ and (D) $\mathrm{P}=0.0004$ (GraphPad Prism software v.9.1). BD, brain death. 

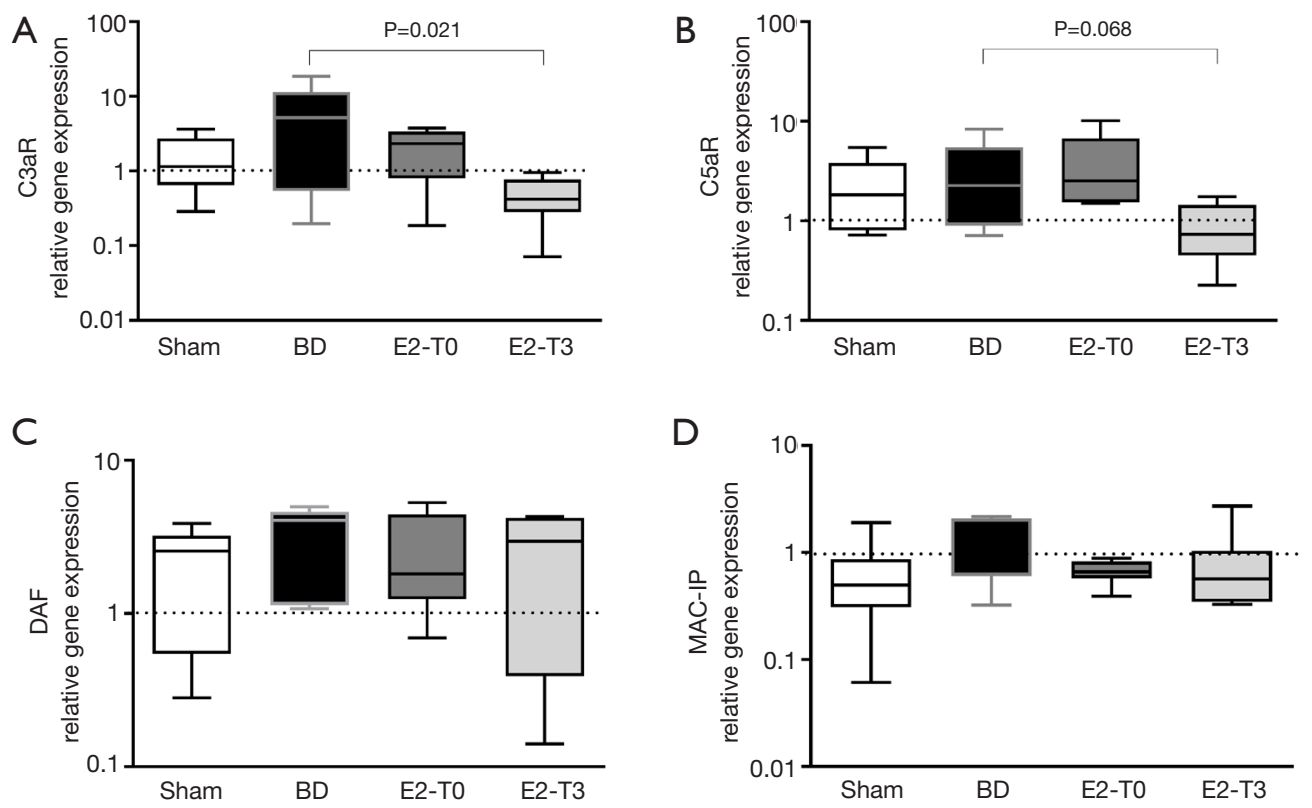

Figure 7 Gene expression of complement receptor for C3a (C3aR) (A) and C5a (C5aR) (B), DAF and MAC-IP in renal tissue. Sham, falseoperated rats; BD, rats submitted to BD; E2-T0, 17 $\beta$-estradiol (E2)-treated rats after confirmation of BD and E2-T3, 17 $\beta$-estradiol (E2)treated rats after $3 \mathrm{~h}$ of confirmation of BD. Values represent the median and $95 \%$ percentile interval for 1 sample/rat and 6 rats/group. Gene expression levels are relative to those in naïve rats. Statistical analysis: Kruskal-Wallis (A) $\mathrm{P}=0.054$, (B) $\mathrm{P}=0.019,(\mathrm{C}) \mathrm{P}=0.281$ and (D) $\mathrm{P}=0.361$ (GraphPad Prism software v.9.1). BD, brain death; DAF, decay-accelerating factor; MAC-IP, membrane attack complex-inhibitor protein.

of $\mathrm{C} 3 \mathrm{aR}$ and $\mathrm{C} 5 \mathrm{aR}$ (Figure $7 A, B$ ).

In relation to the complement inhibitor, there were no important differences in the gene expression of DAF and MAC-IP (Figure 7C,D).

\section{Protein and gene expression of MMP2 and MMP9}

The major physiologic regulators of extracellular matrix degradation in the glomerulus are matrix metalloproteinases. In the analysis of MMP2 protein expression, no significant differences were observed between the Sham and BD groups; however, there was a significant reduction in the E2-T3 group (Figure 8A). Regarding MMP9, after BD, the glomeruli exhibited increased protein expression and there was a reduction in the expression of MMP9 only in the E2T3 group (Figure 8B).

With respect to MMP2 gene expression, no significant differences were observed among the groups (Figure 8C). Similarly, no significant difference was seen in MMP9 gene expression in renal tissue among the groups (Figure $8 D$ ).

\section{Inflammatory mediators}

The inflammatory response induced by brain death is characterized by the local and systemic release of mediators (4). Figure 9 portrays the gene and protein expression of IL-1 $\beta$, IL-6, and VEGF in renal tissue homogenate. In IL- $1 \beta$, both protein and gene expression in renal tissue increased after $\mathrm{BD}$. On the other hand, lower values were found for protein expression in both estradioltreated groups. In addition, lower values were found with the analysis of gene expression of IL-1 $\beta$ in the E2-T3 group.

In relation to IL-6, both gene expression and protein concentrations in renal tissue increased after BD. In contrast, E2 treatment reduced IL-6 gene expression in the E2-T3 group and diminished IL-6 levels in the kidney, showing a significant decrease in the E2-T3 group.

The kidney VEGF protein concentration after $6 \mathrm{~h}$ was reduced in all groups subjected to $\mathrm{BD}$. In relation to gene expression, no significant difference was observed. 


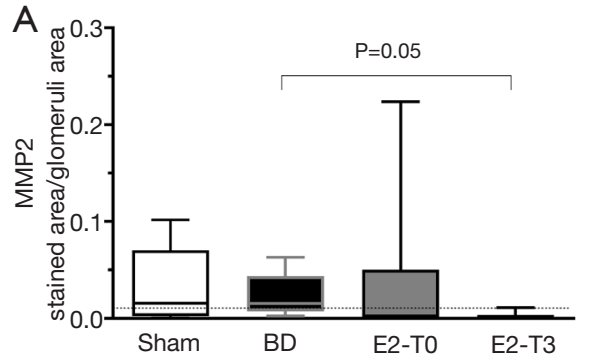

C

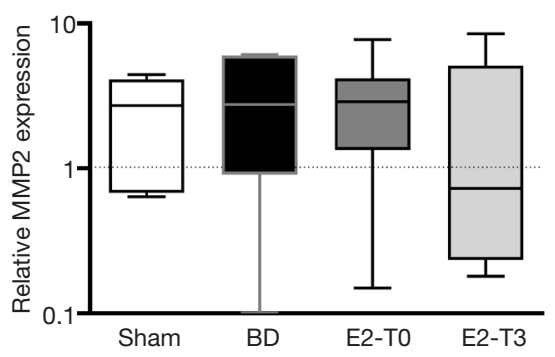

B

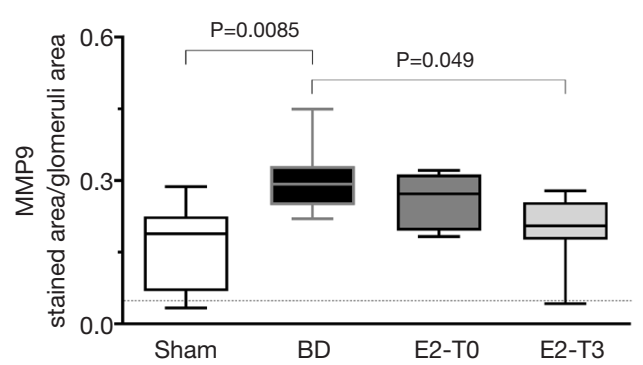

D

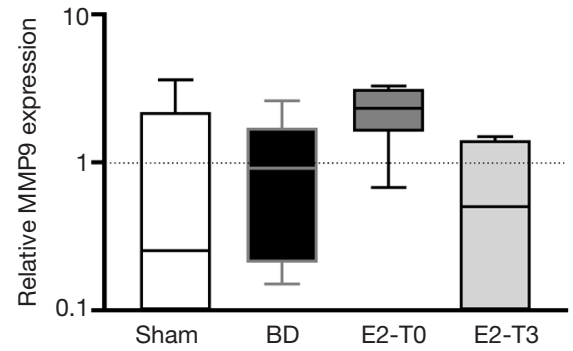

Figure 8 Protein and expression of metalloproteinase 2 (MMP2) (A,C) and metalloproteinase 9 (MMP9) (B,D). Sham, false-operated rats; $\mathrm{BD}$, rats submitted to BD; E2-T0, 17 $\beta$-estradiol (E2)-treated rats after confirmation of BD and E2-T3, 17 $\beta$-estradiol (E2)-treated rats after $3 \mathrm{~h}$ of confirmation of BD. Values represent the median and $95 \%$ percentile interval. (A,B) Imunohistochemical analysis 5 photos/sample and 2 samples/animal. (C,D) Gene expression levels are relative to those in naïve rats in 5 animals/group. Statistical analysis: Kruskal-Wallis (A) $\mathrm{P}=0.043$, (B) $\mathrm{P}=0.011$, (C) $\mathrm{P}=0.924$ and (D) $\mathrm{P}=0.063$ (GraphPad Prism software v.9.1).

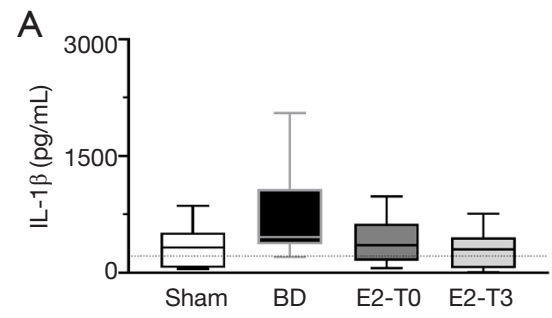

D

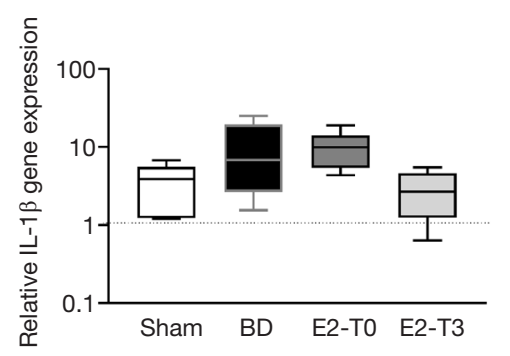

B

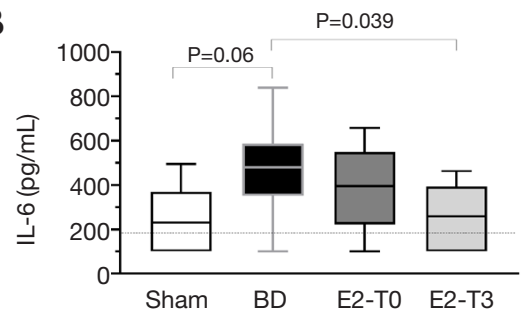

E

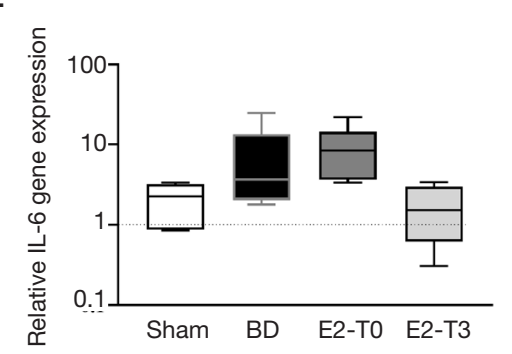

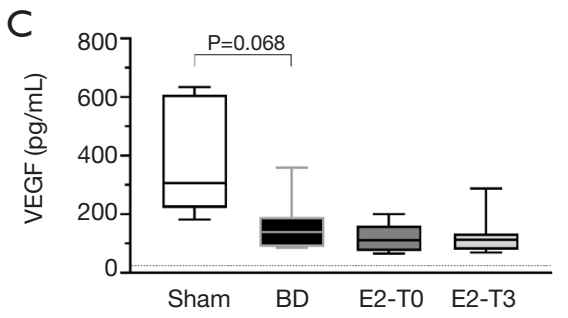

F

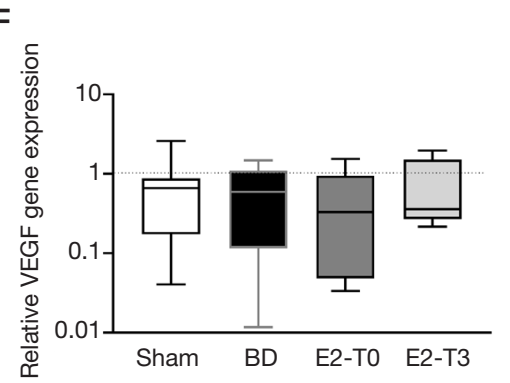

Figure 9 Protein and gene expression of IL-1 $\beta$ (A,D), IL-6 (B,E), and VEGF (C,F) in renal tissue. Sham, false-operated rats; BD, rats submitted to BD; E2-T0, 17 $\beta$-estradiol (E2)-treated rats after confirmation of BD and E2-T3, 17 $\beta$-estradiol (E2)-treated rats after 3 h of confirmation of BD. Values represent the median and $95 \%$ percentile interval for 1 sample/rat and 6 rats/group. Gene expression levels are relative to those in naïve rats. Statistical analysis: Kruskal-Wallis (A) $\mathrm{P}=0.129$, (B) $\mathrm{P}=0.024$, (C) $\mathrm{P}=0.011$, (D) $\mathrm{P}=0.030$, (E) $\mathrm{P}=0.004$ and (F) $\mathrm{P}=0.349$ (GraphPad Prism software v.9.1). 


\section{Discussion}

Brain death leads to a systemic inflammatory response that could be quite severe and which is mediated by ischemic brain released inflammatory mediators and worsened by metabolic changes (4). Previous studies have shown a higher inflammatory female condition in relation to male donor, which was correlated with acute estradiol reduction following $\mathrm{BD}$ (5-7). In BD female rats, treatment with E2 efficiently reduced heart and lung injury, modulated inflammatory cell infiltration, enhanced release of chemokines, and suppressed cardiomyocyte apoptosis $(8,9)$. Female sex hormone concentrations acute reduction after BD may occur probably due to interruption of the hypothalamic-pituitary-ovary axis and affects the control of several nonreproductive tissues including the immune system (5). The treatment applied here was based on previous study and the aim was to use a low therapeutic dose and maintain high serum E2 concentration during the studied period (8).

The model of BD induction used in our study is based on the acute increase of intracranial pressure which is followed by an arterial hypertensive peak. As described in previous study evaluating the effects of E2 treatment in female heart donor following BD (8), no significant changes in cardiac function are observed after estradiol treatment. This can be attributed to the absence of important hemodynamic changes in this BD model.

Results presented here suggest that, in kidneys, E2 treatment was able to prevent and attenuate renal injury in $\mathrm{BD}$ female rats. The treatment protocol was based on previous studies in which continuous infusion of E2 is able to maintain serum levels between 1,500 and $2,000 \mathrm{pg} / \mathrm{mL}$ $(8,9)$. The maintenance of serum estradiol levels, owing to treatment immediately after BD induction, resulted in the non-progression of the renal inflammatory process. E2 exerts its effects through specific receptors (ER), which are present in immune cells and kidney cells. In addition, once the inflammatory process was established, late treatment was shown to be effective in reducing inflammation and renal injury caused by $\mathrm{BD}$, evidenced in the maintenance of renal function; reduction in kidney tissue damage, marked by depletion in KIM-1 expression, deposition/formation of complement system components, and release of inflammatory mediators. Higher concentration of creatinine is associated with reduced kidney function and therefore reflects kidney injury. For this reason, we suggested that E2 has positive effects in kidney function once creatinine levels were reduced. Although compromised kidney function is also associated with increased urea concentration, we do not observe E2 effects and may consider that there are other possible non-renal conditions that contribute to its rise.

The progression of renal injury culminates in the loss of renal function. Acute kidney injury (AKI) is a common clinical issue marked by reduced glomerular filtration rate (GFR) (10-12). In the present study, AKI caused by BD was evidenced by a rise in serum creatinine, as a reflection of an acute decline in the GFR. In addition, although BD did not result in significant changes in the expression of proapoptotic protein Caspase-3, the glomerular injury induced by BD was characterized by upregulation of KIM-1. KIM-1 is a type 1 transmembrane glycoprotein, and at high levels is correlated with a reduction in the GFR and kidney damage (13-15). Studies have reported the protective impact of estradiol treatment in different AKI models $(16,17)$. Abd El-Lateef et al. (17) described the protective effect of E2 in gentamicin-induced AKI, evidenced by lower KIM-1, gamma-glutamyl transferase (GGT), LDH, and cystatin $\mathrm{C}$ serum levels in $\mathrm{OVx}$-female rats. Indeed, we established similar findings; once E2 treatment was able to decrease KIM-1 expression in female kidney tissue after BD.

$\mathrm{BD}$ results in a systemic and local inflammatory response, including complement system activation, cytokine and chemokine release, and leukocyte infiltration into the organs $(3,18-20)$. Complement activation is a relevant mechanism during the pathogenesis of renal injury, affecting renal structure, including the glomerulus, tubuleinterstitium, and/or vasculature (21). Intra-renal complement activation was first characterized and detected by immunostaining renal tissue for $\mathrm{C} 3$ activation components. Kusaka et al. (22) confirmed complement activation in the kidneys of $\mathrm{BD}$ rats as evidenced by $\mathrm{C} 3$ deposition in the glomeruli of BD female rats. In terms of sequence, this is seen through formation of the $\mathrm{C} 3$ - and $\mathrm{C} 5$-convertases and the creation of anaphylatoxins, such as $\mathrm{C} 3 \mathrm{a}$ and $\mathrm{C} 5 \mathrm{a}$. Both anaphylatoxins mediate inflammatory responses through interaction with the specific receptors, $\mathrm{C} 3 \mathrm{aR}$ and $\mathrm{C} 5 \mathrm{aR}$. In parallel, after the cleavage of $\mathrm{C} 3$ and $\mathrm{C} 5$, terminal pathway activation results in the generation of MAC/C 5b-9, forming a lytic pore in the outer cell membrane $(21,23)$. Similar was observed in this study; once BD groups had formation of $\mathrm{C} 3$ and MAC in glomeruli. Despite no reduction in C3 formation, treatment with $\mathrm{E} 2$ downregulated $\mathrm{C} 3 \mathrm{aR}$ and $\mathrm{C} 5 \mathrm{aR}$ expression in renal tissue. Moreover, such treatment prevented the formation of MAC. The generation of complement system components triggers the activation of 
neutrophils as well as monocytes/macrophages, leading to the synthesis of proinflammatory cytokines and renal injury/ apoptosis (23).

Experimental BD models have highlighted IL-1 $\beta$ and IL-6 upregulation during renal acute phase protein synthesis in rats, remarkably complement 3 (C3), $\alpha 2$-macroglobulin, fibrinogen, and haptoglobin $(19,20)$. A similar finding was observed in this study, evidenced by an increase in renal homogenate IL-1 $\beta$ and IL-6 levels along with C3 deposition in renal tissue. Furthermore, the reduction of such inflammatory markers confirms the anti-inflammatory effect of E2 donor treatment in the female kidney. Studies have demonstrated that the binding of E2 to the estrogen receptor can inhibit the transcriptional activity of NF- $\kappa \mathrm{B}$ by inhibiting NF- $\kappa \mathrm{B} \alpha(\mathrm{I} \kappa \mathrm{B} \alpha)$ degradation inhibitors, resulting in a decrease in IL-6 expression $(24,25)$.

The advancement of the inflammatory process is associated with elevated levels of MMPs, and the duration of MMP elevation influences the dimensions of renal damage (26). A vast variety of AKI experimental models have characterized an elevation in the expression of gelatinases MMP-2 and MMP-9 $(27,28)$. Both gelatinases are present in the kidney tissue, degrade components in the glomerular basement membrane, and digest other extracellular matrix structures of the kidney tissue involved in cell survival $(28,29)$. Previous studies have shown that MMP inhibition leads to a reduction in renal injury, apoptosis, cytokine release, and histological damage. In our study, treatment with E2 after $3 \mathrm{~h}$ of BD decreased the glomerular expression of MMP2 and MMP9 in the renal tissue of BD female rats.

This study has certain limitations. We made use of a maintenance time of $6 \mathrm{~h}$, which is usually the standard duration for such an experimental model. However, the benefits of E2 in kidney inflammation and renal tissue injury in BD female rats were observed on early histopathologic and inflammatory results, thus alluding to possible mechanisms. It is also important to consider that receptor levels and dynamics influence tissue responsiveness to steroid hormones. The genomic alterations were less observed and more variable, once they could depend on longer times of rats maintenance. Besides, the increase and maintenance of E2 serum concentration could reduce $\mathrm{ER} \alpha, \mathrm{ER} \beta$, and GPR30 gene expression and protein expression (30,31). In this context, we can suggest that such a reduction could compromise the $\mathrm{E} 2$ protective influence on kidneys in the E2-T0 group. Conversely, the E2-T3 group experienced $3 \mathrm{~h}$ of $\mathrm{BD}$ without treatment and might present, due to $\mathrm{E} 2$ reduction, increased estradiol receptors expression. An increased receptor presence could facilitate the therapeutic effect of the treatment. It is important to point that estradiol exerts rapid effect through its membrane receptor (GPER) that are independent of genomic actions. Further studies are necessary to understand the receptor density influence on E2 treatment effects.

In conclusion, the data presented in this study indicated the efficacy of E2 treatment in preventing and protecting the kidney from tissue injury and inflammation caused by BD. Thus, drug treatment may improve kidney viability for transplantation.

\section{Acknowledgments}

Funding: The author RAJ was a scholarship holder by Conselho Nacional de Desenvolvimento Cientıfico e Tecnologico-(CNPq). LFPM is a fellow researcher of the CNPq.

\section{Footnote}

Reporting Checklist: The authors have completed the ARRIVE reporting checklist. Available at https://dx.doi. org/10.21037/atm-21-1408

Data Sharing Statement: Available at https://dx.doi. org/10.21037/atm-21-1408

Conflicts of Interest: All authors have completed the ICMJE uniform disclosure form (available at https://dx.doi. org/10.21037/atm-21-1408). The authors have no conflicts of interest to declare.

Ethical Statement: The authors are accountable for all aspects of the work in ensuring that questions related to the accuracy or integrity of any part of the work are appropriately investigated and resolved. The experimental protocol was approved by the Animal Subject Committee of Sao Paulo University Medical School (SDC No. 4350/16/016) in compliance with the ARRIVE guidelines and the 'Principles of Laboratory Animal Care' formulated by the National Society for Medical Research and the 'Guide for the Care and Use of Laboratory Animals' prepared by the Institute of Laboratory Animal Resources and published by the National Institutes of Health (NIH Publication No. 86-23, revised 1996). 
Open Access Statement: This is an Open Access article distributed in accordance with the Creative Commons Attribution-NonCommercial-NoDerivs 4.0 International License (CC BY-NC-ND 4.0), which permits the noncommercial replication and distribution of the article with the strict proviso that no changes or edits are made and the original work is properly cited (including links to both the formal publication through the relevant DOI and the license). See: https://creativecommons.org/licenses/by-nc-nd/4.0/.

\section{References}

1. Ghanta M, Jim B. Renal Transplantation in Advanced Chronic Kidney Disease Patients. Med Clin North Am 2016:100:465-76.

2. OPTN/SRTR 2018 Annual Data Report: Preface. Am J Transplant 2020:20:1-10.

3. Bos EM, Leuvenink HG, van Goor H, et al. Kidney grafts from brain dead donors: Inferior quality or opportunity for improvement? Kidney Int 2007:72:797-805.

4. Kumar L. Brain death and care of the organ donor. J Anaesthesiol Clin Pharmacol 2016:32:146-52.

5. Breithaupt-Faloppa AC, Ferreira SG, Kudo GK, et al. Sexrelated differences in lung inflammation after brain death. J Surg Res 2016:200:714-21.

6. Simão RR, Ferreira SG, Kudo GK, et al. Sex differences on solid organ histological characteristics after brain death. Acta Cir Bras 2016:31:278-85.

7. Ferreira SG, Armstrong-Jr R, Kudo GK, et al. Differential Effects of Brain Death on Rat Microcirculation and Intestinal Inflammation: Female Versus Male. Inflammation 2018:41:1488-97.

8. Armstrong-Jr R, Ricardo-da-Silva FY, Correia CJ, et al. Treatment with $17 \beta$-estradiol protects donor heart against brain death effects in female rat. Transpl Int 2020:33:1312-21.

9. Ricardo-da-Silva FY, Armstrong R Jr, Vidal-Dos-Santos M, et al. 17ß-Estradiol Treatment Protects Lungs Against Brain Death Effects in Female Rat Donor. Transplantation 2021:105:775-84.

10. Havasi A, Borkan SC. Apoptosis and acute kidney injury. Kidney Int 2011:80:29-40.

11. Thadhani R, Pascual M, Bonventre JV. Acute renal failure. N Engl J Med 1996:334:1448-60.

12. Basile DP, Anderson MD, Sutton TA. Pathophysiology of acute kidney injury. Compr Physiol 2012:2:1303-53.

13. Ichimura T, Bonventre JV, Bailly V, et al. Kidney injury molecule-1 (KIM-1), a putative epithelial cell adhesion molecule containing a novel immunoglobulin domain, is up-regulated in renal cells after injury. J Biol Chem 1998:273:4135-42.

14. Bonventre JV. Kidney injury molecule-1: a translational journey. Trans Am Clin Climatol Assoc 2014:125:293-9.

15. Sabbisetti VS, Waikar SS, Antoine DJ, et al. Blood kidney injury molecule- 1 is a biomarker of acute and chronic kidney injury and predicts progression to ESRD in type I diabetes. J Am Soc Nephrol 2014:25:2177-86.

16. Iran-Nejad A, Nematbakhsh M, Eshraghi-Jazi F, et al. Preventive role of estradiol on kidney injury induced by renal ischemia-reperfusion in male and female rats. Int $\mathrm{J}$ Prev Med 2015:6:22.

17. Abd El-Lateef SM, El-Sayed EM, Mansour AM, et al. The protective role of estrogen and its receptors in gentamicin-induced acute kidney injury in rats. Life Sci 2019:239:117082.

18. Bouma HR, Ploeg RJ, Schuurs TA. Signal transduction pathways involved in brain death-induced renal injury. Am J Transplant 2009:9:989-97.

19. Damman J, Nijboer WN, Schuurs TA, et al. Local renal complement $\mathrm{C} 3$ induction by donor brain death is associated with reduced renal allograft function after transplantation. Nephrol Dial Transplant 2011:26:2345-54.

20. Watts RP, Thom O, Fraser JF. Inflammatory signalling associated with brain dead organ donation: from brain injury to brain stem death and posttransplant ischaemia reperfusion injury. J Transplant 2013:2013:521369.

21. McCullough JW, Renner B, Thurman JM. The role of the complement system in acute kidney injury. Semin Nephrol 2013:33:543-56.

22. Kusaka M, Pratschke J, Wilhelm MJ, et al. Early and late inflammatory changes occurring in rat renal isografts from brain dead donors. Transplant Proc 2001:33:867-8.

23. Poppelaars F, Seelen MA. Complement-mediated inflammation and injury in brain dead organ donors. Mol Immunol 2017:84:77-83.

24. Kanda N, Watanabe S. 17beta-estradiol, progesterone, and dihydrotestosterone suppress the growth of human melanoma by inhibiting interleukin-8 production. J Invest Dermatol 2001:117:274-83.

25. Lesmeister MJ, Jorgenson RL, Young SL, et al. 17Betaestradiol suppresses TLR3-induced cytokine and chemokine production in endometrial epithelial cells. Reprod Biol Endocrinol 2005:3:74.

26. Lenz O, Elliot SJ, Stetler-Stevenson WG. Matrix 
metalloproteinases in renal development and disease. J Am Soc Nephrol 2000:11:574-81.

27. Basile DP, Fredrich K, Weihrauch D, et al. Angiostatin and matrix metalloprotease expression following ischemic acute renal failure. Am J Physiol Renal Physiol 2004:286:F893-902.

28. Bengatta S, Arnould C, Letavernier E, et al. MMP9 and SCF protect from apoptosis in acute kidney injury. J Am Soc Nephrol 2009:20:787-97.

29. Ihtiyar E, Yaşar NF, Erkasap N, et al. Effects of doxycycline on renal ischemia reperfusion injury induced

Cite this article as: Armstrong-Jr R, Ricardo-da-Silva FY, Vidal-dos-Santos M, Correia CJ, Anunciação LF, Coutinho e Silva RS, Moreira LFP, Leuvenink HGD, Breithaupt-Faloppa AC. Protective role of $17 \beta$-estradiol treatment in renal injury on female rats submitted to brain death. Ann Transl Med 2021;9(14):1125. doi: 10.21037/atm-21-1408 by abdominal compartment syndrome. J Surg Res 2011:167:113-20.

30. Haas E, Meyer MR, Schurr U, et al. Differential effects of 17 beta-estradiol on function and expression of estrogen receptor alpha, estrogen receptor beta, and GPR30 in arteries and veins of patients with atherosclerosis. Hypertension 2007:49:1358-63.

31. Nephew KP, Long X, Osborne E, et al. Effect of estradiol on estrogen receptor expression in rat uterine cell types. Biol Reprod 2000:62:168-77. 